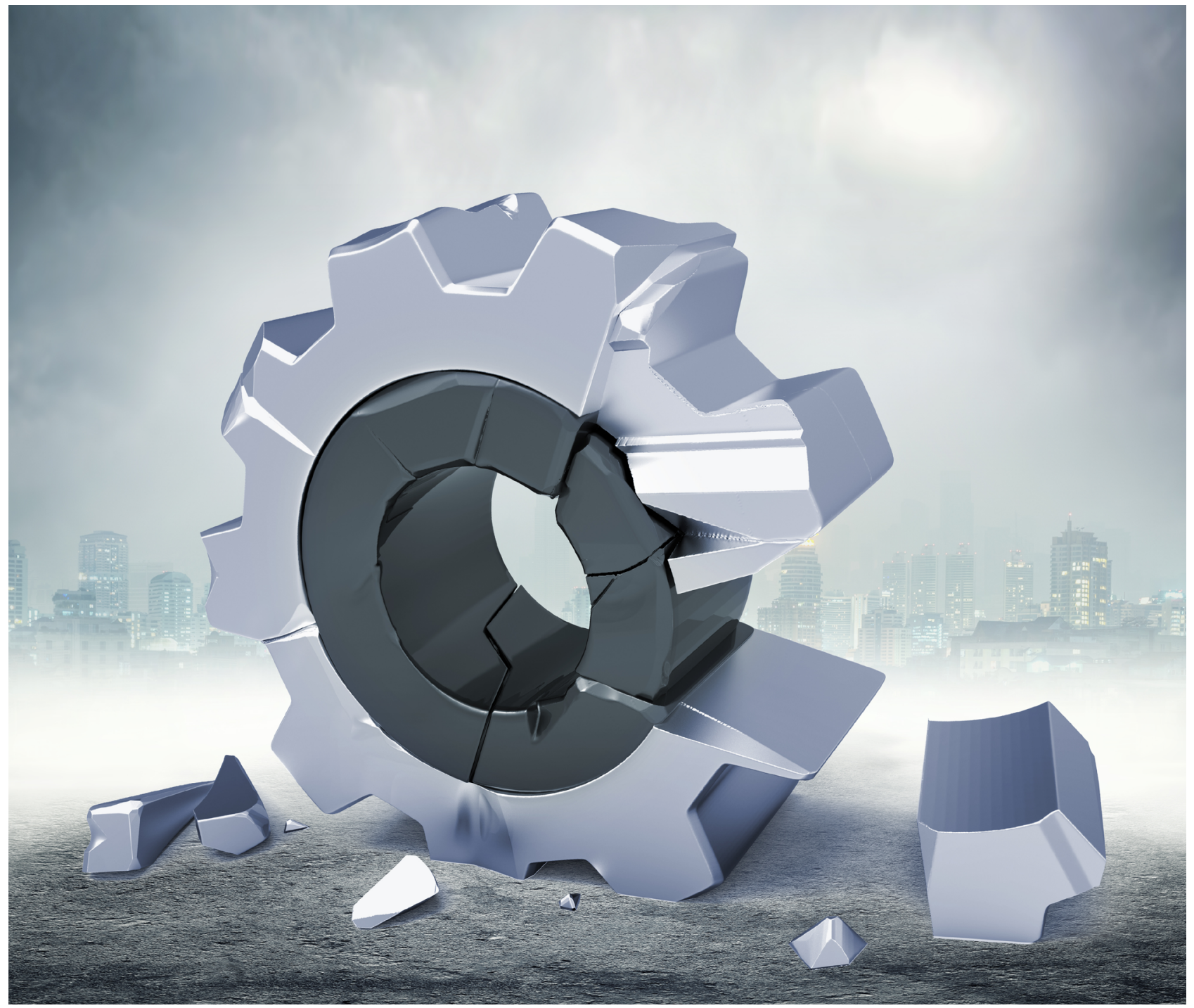

\title{
SABEMOS O QUE ESTAMOS FAZENDO?
}

GERENCIAR ORGANIZAÇÕES COMO MÁQUINAS TRAZ A PERCEPÇÃO CONFORTÁVEL DE QUE A REALIDADE PODE SER CONTROLADA, MAS É RECONHECENDO A COMPLEXIDADE QUE PODEMOS NOS CAPACITAR A TOMAR DECISÕES MAIS CONSCIENTES E CONSEQUENTES. 


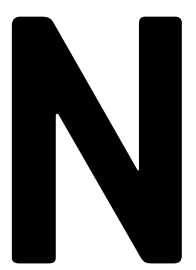

ós, gestores, nos deparamos a todo o momento com a necessidade de tomar decisões estratégicas sobre como conduzir empresas sob nossos cuidados. Quase sempre, contudo, não há tempo para refletir sobre os pressupostos nos quais nos baseamos para tomar decisões. Gostamos de acreditar que estas sejam racionais, logicamente consistentes e plenamente justificáveis. Desse modo, sentimo-nos mais seguros e fortalecemos a crença de que estamos no controle da situação.

Os fatos, no entanto, teimam em nos contradizer. Resistimos em reconhecer que o curso dos acontecimentos frequentemente escapa às nossas mãos e que a realidade é mais ambígua e complexa do que gostaríamos. Múltiplos fatores afetam os resultados que pretendemos alcançar, e nossa capacidade de influenciá-los é limitada.

Quando desenvolvemos nossos raciocínios para a tomada de decisões, invariavelmente nos baseamos em metáforas que nos ajudam a explicar como as organizações funcionam. É quase tão natural e automático recorrer a esses modelos mentais que não refletimos sobre eles. Apesar disso, eles condicionam o modo como formulamos questões, organizamos nossas ideias e chegamos a conclusões.

É comum, na prática em gestão, pensarmos nas empresas como máquinas, isto é, como uma estrutura racional de tarefas e atividades, com relações ordenadas e claramente definidas entre as partes, planejada e projetada para atingir determinados fins e na qual todos devem comportar-se de maneira predeterminada.

A máquina organizacional geralmente envolve estrutura hierárquica de cargos e funções, cadeia direta de comando, autoridade geral centralizada, normas e processos padronizados, especialização de tarefas, treinamento sistemático, monitoramento, supervisão e controle, disciplina e obediência à administração.

Em termos analíticos, prevalecem a racionalidade técnica e instrumental e a crença na existência de relações objetivas de causa e efeito capazes de orientar as decisões de gestão e determinar, em larga medida, o desempenho organizacional. Nessa perspectiva, as decisões gerenciais devem basear-se no acúmulo de informações e na aplicação de critérios técnicos, tal como em um exercício de engenharia.

Os valores e princípios subjacentes à metáfora da máquina organizacional derivam em parte da burocracia weberiana - precisão, velocidade, clareza, regularidade, confiabilidade e eficiência - e em parte do taylorismo e da administração clássica - planejamento, organização, comando, coordenação e controle. Ordem e regulação são consideradas
DIVERSAS METÁFORAS ALTERNATIVAS COMO AS DO ORGANISMO E DO CÉREBRO - TÊM SIDO DESENVOLVIDAS PARA TENTAR SUPERAR AS LIMITAÇÕES DA METÁFORA DA MÁQUINA ORGANIZACIONAL E PARA APREENDER DE MODO MAIS ABRANGENTE A COMPLEXIDADE DO FUNCIONAMENTO DAS ORGANIZACCOOES.

imprescindíveis para assegurar coesão, estabilidade e integração às empresas.

Os pressupostos mecanicistas nos quais a metáfora da máquina se assenta constituem uma espécie de paradigma da gestão organizacional na prática. Muitos gestores de empresas de diferentes portes e setores de atividade não hesitariam em apontar a máquina organizacional como um ideal a ser perseguido.

\section{LIMITES DA METÁFORA MECANICISTA}

Não há nada de errado, a princípio, em recorrer a metáforas para compreender melhor o mundo em que vivemos. Empregamos com frequência recursos simbólicos para tornar a nossa realidade cognitivamente apreensível e cognoscível. É preciso, contudo, ter sempre em mente que metáforas são aproximações: contam somente uma parte da história; revelam apenas parcialmente a natureza do fenômeno que buscamos entender, iluminando alguns de seus aspectos, enquanto outros são obscurecidos.

Nossa obsessão por soluções prontas, respostas rápidas e resultados imediatos leva-nos com muita frequência a esquecer que estamos raciocinando metaforicamente. Passamos, então, a esperar e, no fundo, a desejar que as empresas se comportem de modo rotineiro, eficiente, confiável e previsível, como máquinas organizacionais.

Embora todos reconheçamos, por exemplo, o papel fundamental das pessoas na consecução das metas e dos objetivos que buscamos, poucas vezes o fator humano é efetivamente considerado em toda a sua complexidade como um dos determinantes do desempenho organizacional. $\mathrm{Na}$ prática, muitos gestores acreditam que as pessoas, de uma forma ou de outra, devem incorporar-se ao funcionamento da máquina organizacional. 


\section{QUESTÕES PARA TRANSPORTAR O GESTOR DA MÁQUINA ORGANIZACIONAL À ABORDAGEM INTERPARADIGMÁTICA}

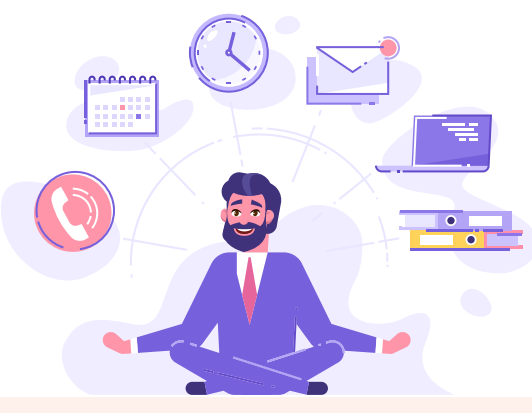

1. Em que medida e como fatores externos podem afetar os resultados esperados?

2. Quais são as implicações de uma decisão para clientes e fornecedores e, mais amplamente, para governo e sociedade?

3. Como os funcionários receberão a decisão? Haverá engajamento ou resistência? O clima organizacional favorecerá ou dificultará a implementação da decisão?

4. Os funcionários estão preparados para desempenhar o papel que lhes caberá?

5. Os processos de negócio são compatíveis com a decisão tomada ou podem inviabilizar sua implementação?

6. Qual mensagem a decisão transmitirá e quais seus impactos sobre como a empresa e os gestores são percebidos tanto interna quanto externamente?

7. Como os grupos de interesse, as redes de influência e as relações de poder existentes na empresa serão afetados pela decisão e como reagirão a ela?

8. Há coerência entre as motivações subjacentes à decisão tomada, a narrativa construída para apresentá-la e seus efeitos práticos?

9. A empresa está apta a identificar inconsistências na decisão ou falhas em sua implementação e promover ações para corrigi-las?

10. A decisão tomada está alinhada aos valores e princípios declarados pela empresa e à cultura organizacional?

O esquecimento do caráter metafórico da máquina organizacional também pode conduzir a simplificações excessivas da realidade. Muitos problemas complexos das empresas são resolvidos em planilhas de Excel com uma facilidade assustadora. Números são modificados nas projeções financeiras ou nos diagramas de valor, como se não implicassem nada além de uma simples decisão gerencial. Reduções de despesas e cortes de pessoal são decididos como se os impactos se restringissem ao efeito imediato almejado e não fossem capazes de produzir também consequências indesejadas, na maior parte das vezes negativas o suficiente para neutralizar o benefício de curto prazo alcançado com a redução de custos, ou, o que é ainda pior, comprometer seriamente a capacidade de geração de valor da empresa no futuro.

A metáfora da máquina organizacional apresenta limitações significativas e impõe sérias dificuldades aos gestores. Os imperativos de ordem e regulação subjacentes a esse modelo mental pressupõem organizações estáveis e previsíveis, favorecendo estruturas mais rígidas e menos suscetíveis a mudanças. Em ambientes como esses, há pouco estímulo e oportunidade para criatividade e inovação. Levando em conta que criatividade e inovação são apontadas como fundamentais para a competitividade das empresas, estamos diante de uma contradição difícil de ser superada.

\section{PARADIGMAS DA COMPLEXIDADE}

No campo acadêmico, a metáfora da máquina organizacional, bem como seus pressupostos mecanicistas, vem sendo questionada há muito tempo. Embora algumas vertentes mais ortodoxas ainda se vinculem explícita ou implicitamente a esse modelo, suas limitações tornaram-se evidentes para a maior parte dos teóricos e pesquisadores em administração ao longo das últimas décadas.

Diversas metáforas alternativas têm sido propostas, testadas e desenvolvidas para tentar superar as limitações da 


\section{SE, POR UM LADO, A SUPERAÇÃO DOS PRESSUPOSTOS MECANICISTAS E DA METÁFORA DA MÁQUINA NOS ASSUSTA E AMEAÇA, POR OUTRO PODE NOS LEVAR A UMA COMPREENSÃO MAIS AMPLA DO FUNCIONAMENTO DAS ORGANIZACOÕES E DOS FATORES QUE IMPACTAM O DESEMPENHO ORGANIZACIONAL.}

metáfora da máquina organizacional e apreender de modo mais abrangente a complexidade do funcionamento das organizações. Ainda que nenhuma, isoladamente, seja capaz de oferecer um quadro completo da dinâmica organizacional, cada uma delas ilumina uma dimensão esquecida pela metáfora da máquina organizacional.

A metáfora do organismo, por exemplo, também largamente empregada, descreve as organizações como sistemas abertos em luta por sobrevivência no ambiente. A metáfora do cérebro concentra-se em aspectos cognitivos, tais como a aprendizagem organizacional. A metáfora da cultura enfatiza os conteúdos simbólicos e informais, bem como a criação de significados compartilhados. A metáfora do sistema político sublinha os conflitos de interesse e de poder dentro das organizações. A metáfora da prisão psíquica baseia-se em teorias psicanalíticas para compreender como as empresas conseguem vincular seus membros a elas, por meio de mecanismos inconscientes. A metáfora do fluxo e transformação enfatiza os processos, a autorreferência e a imprevisibilidade. A metáfora do instrumento de dominação destaca a exploração, o controle e a distribuição desigual de poder nas organizações.

O questionamento à metáfora da máquina organizacional e a consequente diversificação de perspectivas que se desenvolveu no campo acadêmico não se verificaram com a mesma intensidade na prática em gestão. Nós, gestores organizacionais, ainda não submetemos nossos pressupostos a um exame crítico mais aprofundado nem incorporamos ao nosso repertório analítico de forma consequente as perspectivas alternativas sobre a dinâmica organizacional que hoje temos à disposição.

Talvez esse apego resistente por parte dos gestores aos pressupostos mecanicistas e ao modelo mental de máquina organizacional decorra do fato de que ambos reafirmam a crença de que o destino das empresas esteja em nossas mãos. Pressupor que os fatores que afetam o desempenho organizacional são conhecidos e controláveis legitima a ideia de que basta garantir que a máquina organizacional funcione perfeitamente para que os resultados esperados sejam alcançados.

Reconhecer, em vez disso, que as organizações não são máquinas e que o desempenho organizacional depende de fatores que não controlamos expõe o caráter contingente da gestão e coloca em xeque a perspectiva voluntarista do suposto papel determinante do gestor no sucesso ou no fracasso das empresas.

Se, por um lado, a superação dos pressupostos mecanicistas e da metáfora da máquina nos assusta e ameaça, por outro, pode nos levar a uma compreensão mais ampla do funcionamento das organizações e dos fatores que impactam o desempenho organizacional. Trata-se de considerar uma realidade mais complexa e desafiadora, sobre a qual nosso poder de atuação é limitado. Ao reconhecê-la como tal, porém, capacitamo-nos a tomar decisões mais conscientes e consequentes, bem como a gerir empresas com um conhecimento mais abrangente e aprofundado sobre a dinâmica organizacional.

Uma abordagem interparadigmática, espécie de síntese dialética das metáforas e dos paradigmas propostos pela literatura acadêmica, constitui um referencial de análise mais abrangente, denso e diversificado. As questões apresentadas no quadro deste artigo, embora não exaustivas, são exemplos de indagações que podem contribuir para o desenvolvimento dessa abordagem. Ao considerá-las em nossas decisões e na gestão das empresas, talvez possamos afirmar, de forma menos arriscada, que sabemos o que estamos fazendo.

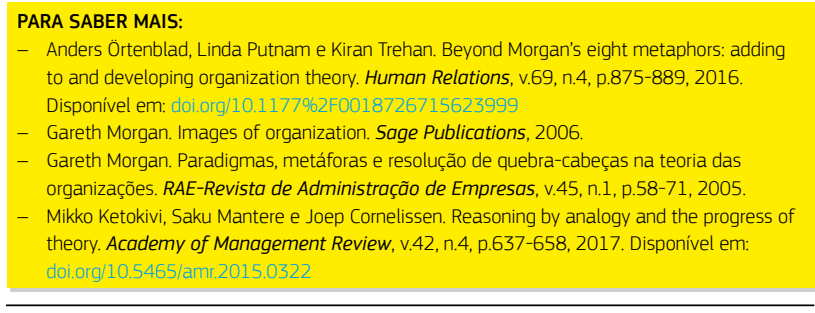

FABIANO MONETTI > Mestre em Sociologia pela PUC-SP e doutorando em Administração de Empresas pela FGV EAESP > fabiano.monetti@fgv.edu.br 